\title{
PREZENŢA BAZEI APELATIVE DE SUBSTRAT ÎN REPERTORIUL ONOMASTIC AL RECENSÄMINTELOR POPULAŢIEI MOLDOVEI DIN ANII 1772-1773 ŞI 1774
}

\author{
Ecaterina PLeşCA \\ Institutul de Filologie Română „B. P.-Hasdeu” al MEC
}

\begin{abstract}
Rezumat. In comunicarea de faţă ne-am propus să urmărim transferul în onomastică al cuvintelor autohtone din limba română notate în registrele Recensămintelor populaţiei Moldovei din anii 1772-1773 şi 1774. Cercetările au arătat că în sursa dată au fost înregistrate antroponime formate doar de la 35 dintre apelativele de origine autohtonă (baci, balaur, balegă, baltă, bâlc, bâr, brad, brânză buză, cioară, cioc, ciut, copac, cursă fărâmă, fluier, gata, ghimpe, groapă, grumaz, leurdă, mare, măgar, mărar, mânz, moş, murg, pârâu, pupăză, rață, strungă, ţap, ţeapă, urdă, vatră). Acestea şi derivatele lor apar ca bază apelativă la prenume, supranumel porecle, patronimel nume de familie. Repartiţia lor geografică diferă de la ţinut la ţinut. La est de Prut numărul lor este mai mic decât în restul Moldovei istorice. Unele dintre ele nu apar ca bază apelativă în acest spaţiu de răspândire a limbii române.
\end{abstract}

Cuvinte-cheie: antroponim, bază apelativă, cuvânt de substrat, derivat, repertoriu onomastic, recensământul populaţiei Moldovei etc.

Abstract. In the present communication we set out to pursue transfer in onomastics of nativel substrate words noted in the registers Census of the population of Moldavia from 1772-1773 and 1774. Research shows that anthroponyms have been recorded in this sourse only from 35 substrate words (baci, balaur, balegă, baltă, bâlc, bâr, brad, brânză , buză , cioară, cioc, ciut, copac, cursă , fărâmăa fluier, gata, ghimpe, groapă, grumaz, leurdă, mare, măgar, mărar, mânz, moş, murg, pârâu, pupăză rață, strung, țap, țeapă, urdă, vatră). These and their derivatives appear as an appellation basis first name, last name, nickname. Their geographical distribution differs from county to county. East of the Prut their number is smaller than in the rest of historical Moldova. Some of them do not appear as an appellation base in the repertoire of anthroponyms registered in this spase for spreading the Romanian language.

Keywords: anthroponyms, appellation base, substrate word, derivative, onomastic repertoire, census of the population of Moldavia etc.

1.1. Transferul apelativelor în onomastică se face prin păstrarea bazei apelative, condiţie în care cuvântul supus transferului îşi păstrează forma şi, o perioadă oarecare, conţinutul său intern. Mai mult ca atât, unitatea onomastică nou formată capătă trăsăturile limbii locale, adică se poate deosebi prin particularităţi dialectale constituite diacronic şi teritorial 
(fonetice, morfologice, de formare a cuvintelor, semantice ş. a.). Respectiv, onomastica păstrează un material de limbă foarte valoros pentru istoria limbii, dialectologie, geografia lingvistică, etnolingvistică, sociolingvistică, istorie, sociologie etc. De aici şi locul foarte important pe care îl ocupă această disciplină în cercetarea fundamentală a limbii privind moştenirile din substrat. Aplicarea metodei onomastice în cercetarea substratului limbii române a dat rezultate însemnate (de ex., prin examinarea repartiţiei teritoriale a oiconimelor formate cu sufixele -dava şi -bria s-a putut face delimitarea între tracii de sud şi de nord, precum şi limitele spaţiale populate de aceştia.

Din vocabularul autohton al limbii române au ajuns până în zilele noastre cca 90 de cuvinte apelative de provenienţă sigură din substrat (cuvinte-radical şi derivate). In opinia lui Gr. Brâncuş, ,e de presupus că în epoca românei comune (perioada de dinainte de separaţia dialectală sud- şi nord-dunăreană, aproape toate cuvintele moştenite din substrat erau răspândite pe întreg teritoriul de limbă română..." (Brâncuş, 1995, p. 18), iar capacitatea de transfer în onomastică, este apreciată drept una dintre trăsăturile cele mai însemnate ale vocabularului autohton (ibidem, p. 19).

1.2. În anii 2016-2018, cu scopul de a completa datele privitoare la tema de cercetare Cuvinte de substrat examinate din perspectiva geografiei lingvistice (în baza atlaselor lingvistice apărute la Chişinău), ne-am propus să apelăm la date oferite de onomastică şi am procedat la excerptarea antroponimelor formate de la o bază apelativă de substrat înregistrate în repertoriul Recensămintelor populaţiei Moldovei din anii 1772-1773 şi 1774 $(-\mathrm{RP})$. Ar fi de observat că recensămintele la care ne referim au fost efectuate în timpul operaţiunilor militare ruseşti antiotomane pe teritoriul Moldovei.

Potrivit materialelor RP, listele cetăţenilor sunt prezentate pe ţinuturi (21 la număr), ocoluri, localităţi, moşii, mănăstiri şi schituri. În total au fost înregistrate 1977 aşezări (sate şi cătune), printre care şi 19 târguri. În afara acestora, au fost notate 195 de sate pustii, locuitorii cărora le-au părăsit sau au fost duşi în robie în timpul incursiunilor tătarilor sau ale turcilor. Dintre cele 1958 de sate populate, 1430 aparţineau boierilor (şi răzeşilor), 395 mănăstirilor, 16 - negustorilor, 117 - visteriei statului (Kotenko, 1957, p. 55). Din totalul de 92.873 de gospodării, înregistrate în timpul RP, locuite erau 88.730 , iar nelocuite 4.143 . Numărul total al populaţiei înregistrate în timpul recensămintelor a fost de 443.650 persoane (ibidem, p. 55-56), (după alte date în Moldova din a doua jumătate a secolului al XVIII-lea locuiau peste 600.000 persoane, lucru ce pare a fi adevărat, dacă ar fi să luăm în consideraţie persoanele refugiate din calea armatei ruseşti, stabilite pe teritoriul ţării (din cauza impozitelor mari, a îndatoririlor puse pe umerii băştinaşilor privind asigurarea armatei ruse cu alimente, animale de tracţiune, precum şi obligativitatea corvodelor etc.). Respectiv, în Moldova dintre Prut şi Nistru densitatea populaţiei era cea mai joasă.

Sursa a fost selectată din următoarele motive: 1) onomastica păstrează fapte foarte vechi conservate în nume proprii (antroponime şi toponime); 2) cu 
toate lacunele lui, acest registru de evidenţă a populaţiei este mai complet decât alte asemenea registre; 3 ) este cea mai accesibilă dintre sursele (de acest fel) ce reflectă perioade mai vechi din istoria Moldovei, fiind editată în volum aparte la Chişinău etc. Din perspectivă lingvistică, valoarea cea mai importantă este că structura materialul antroponimic din Recensăminte reprezintă antroponime ce reflectă etapele de constituire a numelui de persoană: prenume, prenume + supranume/ poreclă, prenume + variante ale formulei filiaţiei, prenume + nume de familie/ patronim - structuri care ne permit să surprindem numele de familie în constituirea sa. Prin urmare, la sf. sec. al XVIII-lea numele de familie nu era încă o componentă obligatorie în identificarea unui individ. Individualizarea se făcea adăugându-se la prenume un determinativ-identificator format de la prenumele părintelui (a viţei de neam), al localităţii, a meşteşugului practicat, al ocupaţiei ş.a. care trebuiau să-l deosebească de semenii săi din comunitatea sătească.

Întrucât este vorba de anii '70 ai sec. al XVIII-lea, au fost înregistraţi doar stăpânii gospodăriilor/ capii de familie, adică antroponimia, în bună parte, este „bărbătească”. Nume de persoană feminine apar rar - în cazul când lipseşte bărbatul-soţ sau bărbatul-tată în gospodărie, precum şi atunci când numele de familie (-NF) sau supranumele respectiv a fost moştenit de la predecesori.

1.3. Din motivele prezentate mai sus, ne-am propus să folosim drept sursă Recensămintele populaţiei Moldovei din anii 1772-1773 şi 1774 - sursă ce cuprinde material antroponimic şi toponimic notat pe întreaga întindere geografică a Moldovei medievale şi care se referă la toţi cetăţenii ei. Astfel, în marea lor majoritate, antroponimele înregistrate reprezintă populaţia rurală, care accepta schimbările mai greu. Faptul dat reprezintă o realitate lingvistică de epocă veche, fixată de cca 250 de ani în urmă, înainte de declanşarea primenirilor aduse de secolul al XIX-lea.

2. În cele ce urmează, vom prezenta, în ordine alfabetică, antroponimele formate de la o bază apelativă de substrat din repertoriul RP.

Baci. În repertoriul onomastic al $\mathrm{RP}$ acesta este cunoscut ca supranume, determinativ exprimând ocupaţia. Supranumele baci a fost alăturat prenumelui persoanelor care ocupau funcţia de baci la stână, dacă nu chiar pe cea de cioban, căci semnificaţia cea mai veche a cuvântului este de „cioban” (Brâncuş, 1983, p. 31). Funcţia supranumelui era de a individualiza între ele persoane care purtau acelaşi prenume sau persoana care practica ocupaţia sau meşteşugul desemnat. La est de Prut acesta a fost notat ca nume determinativ pe lângă prenume, notat cu minusculă, în ţinuturile: Hotin - Toader, baciul (II, p. 114; s. Costicenii), Cernăuţii Ion, baciul, Sandul, baciul (I, p. 383; s. Cotul lui Baenschii); Grecenii Constantin, baciul (II, p. 221; s. Goteştii), Orhei-Lăpuşna - Savil, baciul (II, p. 459; s. Ustia).

Mai puţine sunt cazurile de a fi notat în formule ce exprimă filiaţia, în care apare ca supranume: Costandin sân baciul (II, p. 411; s. Sărătenii, ţin. Orh.-L.). O altă atestare este antroponimul feminin Băcioae, format de la 
numele soţului cu ajutorul sufixului -oaie, prin moţiune (II, p. 462; s. Lopatna, ţin. Orh.-L.).

Se pare, acesta, ca şi antroponimul Badea, a putut fi utilizat ca prenume.

Balaur(e). În antroponimia RP a fost notat ca NF, în două variante fonetice: Bălaur (II, p. 119; s. Râncaciul, ţin. Hot.); Bălaor (II, p. 456; s. Făureştii, ţin. Orh.-L.).

Baligă. $\mathrm{Cu}$ transfer în onomastică, autohtonul baligă a fost notat o singură dată, cu majusculă, ca NF, în antroponimul Vasâle Băligă (II, p. 170; s. Zalucea, ţin. Hot.). La originea sa, este un supranume apelativ.

Baltă. În RP autohtonul baltă este bine prezentat ca bază apelativă de la care s-au format nume de persoană. Ca prenume nu se întâlneşte. Trecerea lui în antroponomastică s-a făcut prin intermediul valorii de supranume/ NF. În numele bipartite de persoană, Baltă e notat cu majusculă, înlocuind patronimul, în s-le Beşănăuţii, Feteştii, Iadeniţa din ţin. Hotin (II, p. 160, 164;) şi în s-le Zgheroaea şi Drăguşenii din ţin. Orhei-Lăpuşna (II, p. 442, 445) toate prezentând forme omofone cu baza apelativă baltă, nearticulate. La acestea se adaugă, tot ca NF, derivatele Băltean şi Bălteanu (II, p. 443, s. Sălăjenii; p. 416, Târgul Orheiului, ţin. Orh.-L.), precum şi Băltăţescu (II, p. 166; s. Mărcăuţii, ţin. Hot.). Formele date au la origine nume topice.

Bâlc. Autohtonul bâlc este cunoscut în toponimie ca entopic cu variantele fonetice: bălc, barc, bărc, bârc. Transferul acestuia în onomastică s-a produs prin forma de bază, ca supranume/ NF. Astfel, la est de Prut, ca NF, au fost notate: Bâlcu (II, p. 130; s. Prihorodul, țin. Hot.): Bărculeasă (II, p. 456; s. Goianul, ţin. Orh.-L.), format prin moţiune de la NF masculin Barcul/ Bărcul. Mai multe la număr sunt antroponimele derivate: Bărcar (II, p. 466; s. Oleşcanii) şi Bărcari (II, p. 470; s. Voroteţile); Bărcuţă (II, p. 459; s. Criulenii), Bârcăonu (II, p. 454; s. Sarămârza) şi Burcan / Bu[/ă]rcan (II, p. 470 ; s. Ocna) - toate notate în ţin. Orhei-Lopuşna.

Bâr. În limba română bâr este un cuvânt, interjecţie, cu care se cheamă, se îndeamnă sau se alungă/ gonesc oile. El reprezintă o bază onomatopeică de la care s-au format mai multe derivate, acoperind întreg spaţiul de limbă română încă din vechime. În listele RP au fost notate antroponime formate de la un substantiv bâră/ bârcă „oaie”: a bârâi vb. ,a mâna oile strigându-le „bâr”, bârâiac „miel” ș. a.

Cele mai multe înregistrări în RP le avem în antroponime din ţin. Hotin, cu forma Bârcă (identică cu derivatul apelativ): Bârcă moşneagul, Toader sin Bârcăa, precum şi NF Bârcă (II, p. 113, Negrinţii; 155, Hrămăncăuţii; 166, Bulboaca, ţin. Hot.; II, p. 219; s. Larga, ţin. Gr.). Ca NF, trecut prin valoarea de supranume, a fost notat derivatul bârâiac $(<$ bârâi vb. $<$ bâr) cu varianta Bărăeac (II, p. 445; s. Drăguşenii, ţin. Orh.-L.); cf. oiconimul Bărăeacu (I, p. 93; II, p. 422; ţin. Orh.-L.).

Brad. In stânga Prutului, baza apelativă brad o avem notată în NF Brăduţan (II, p. 168, 169; s. Criva, ţin. Hot.), formă derivată de la un toponim Brăduţ cu suf. -an. Prin urmare, avem un antroponim derivat toponimic 
format de la numele localităţii. În cazul dat, numele satului era $B r a ̆ d u t ̧ u(l)$ sau Brăduţii, (*Brăduţ(ii), oiconim nefixat în RP).

În Târgul Hotinului a fost notat NF Bradunschi, formă slavizată a NF romănesc Brădun (brad + -un + -schi) (II, p. 179).

Însă cea mai valoroasă formă pentru istoria limbii române, notată în RP, este forma Braz din antroponimul Vasile Braz (I, p. 126; s. Cobeşti, ţin. Cern.), care „ne asigură de existenţa variantei originare braz (de la care s-a refăcut de timpuriu sing. brad" (Brâncuş, 1995, p. 26).

Brânză. În RP, baza apelativă de substrat brânză, transferată în onomastică, apare notată în antroponime NF din satele: Highidişul, Boghicenii, Goeanul, Jora de Sus, Târgul Orheiului din ţinutul Orhei-Lăpuşna (II, p. 403, p. 416, p. 419, p. 447, p. 456, 462, precum şi în formula de filiaţie Crăciun zăt Brânzăa, notată în s. Meleşeni (II, p. 403). În ţin. Hotinului, baza apelativă de substrat brânză o avem notată prin derivatele: Brânzei (II, p. 116; s. Marşăniţa; II, p. 131; [Ru]javniţa); Brânzilă (II, p. 157; s. Tăbanul). $\mathrm{Ca}$ antroponim derivat toponimic, o avem fixată în structura antroponimului Axinte ot Brânzeni (II, p. 182), probabil, acelaşi cu s. Brânzenii, ţin. Hotinului.

Buză. În antroponimia de la est de Prut, poate fi considerată una dintre cele mai răspândite baze apelative de substrat cu transfer în onomastică, prin forme simple şi derivate, articulate sau nearticulate. Antroponime NF identice cu baza apelativă buză au fost înregistrate în ţin. Orhei-Lăpuşna.: Buză (II, p. 442, s. Zgheroaea), Buza (II, p. 423, s. Săpotenii), Buzul, (II, p. 401, s. Dişcova; p. 437, s. Peresecina), pe când în ţin. Hotinului a fost înregistrat numai NF Buza (II, p. 143, s. Culişăvca). Mai frecvente sunt antroponimele NF derivate de la baza apelativă buză: Buzatul (II, p. 125, s. Maliniţa, ţin Hot.); Buzilă (II, p. 158, s. Burlăneştii; II, p. 176-177, s. Corjăuţii, ţin. Hot.) şi (II, p. 410, Leuşenii, ţin. Orh.-L.); Buzne (II, p. 213; Frumoasa, ţin. Gr.) şi (II, p. 163; s. Codrenii, ţin. Sor.), Buzun (II, p. 401; s. Dişcova, ţin. Orh.-L.), precum şi NF hibrid Buzurnoiul (din: buzura + suf. sl. -noi), articulat (II, p. 146; s. Lomanceniţa, ţin. Hot.).

Cioară. În antroponimia RP este cunoscut doar ca NF. La est de Prut, antroponime NF Cioară au fost înregistrate în satele Zărneştii, din ţin. Grecenii, Hânceştii, şi Chipercenii, din ţin. Orhei-Lăpuşna. Dintre antroponimele NF derivate de la baza apelativă cioară au fost notate: Ciorâiu (II, p. 218; s. Pelineiu, ţin. Gr.); Cioroiul (ibidem; II, p. 220; s. Larga, ţin. Gr.) şi Ciorescu (II, p. 451; s. Dâncenii, ţin. Orh.-L.).

Cioc. Potrivit datelor RP, la est de Prut, transferul în onomastică a acestuia a fost înregistrat în NF Ciocul, notat în s. Hânceştii, ţin. Orhei-Lăpuşna (II, p. 445) şi în forma derivată Ciocârlan, NF notat în s. Caracuşanii, ţin. Hotinului (II, p. 178).

Ciut. Potrivit RP, în estul Prutului, Ciută a fost notat ca NF nearticulat, o singură dată (II, p. 416; s. Păhărnicenii, ţin. Orh.-L.). Varianta cu ş- îniţial nu a fost înregistrată. 
Copac. Autohtonul copac, ca bază apelativă de substrat, se regăsește în NF Copăcean (II, p. 442; s. Zgheroaea, ţin. Orh.-L.). Este singura atestare în registrele RP.

Cursă. Baza apelativă cursă a fost notată numai în antroponimul Vasâli Cursăi, înregistrat în s. Vornicenii, țin. Orhei-Lăpuşna (II, p. 429).

Fărâmă. Ca baza apelativă, autontonul fărâmă se regăseşte în NF Fărâmă, înregistrat în s-le Nisporenii şi Cârsteştii din ţin. Orhei-Lăpuşna (II, p. 449); precum şi în formele antroponimice derivate: Fărmuş (II, p. 155; s. Rosuşlii, ţin. Hot.) şi Fărman (II, p. 162; s. Târnova, ţin. Hot.).

Fluier. Baza apelativă de substrat fluier se regăseşte numai în derivatul diminutival Flueraş din antroponimele Toader Fluieraş şi Vasâle cumnat Flueraşului (II, p. 169; s. Bălcăuţii, ţin. Hot.).

Gata. Autohtonul gata a fost înregistrat doar în compusul Gurăgata (gură + gata) din formula de filiaţie Onofrei sin Gurăgata (II, p. 173; s. Vancicăuţii, ţin. Hot.).

Ghimpe. Format de la baza apelativă ghimp, a fost notat NF Ghimpul, (II, p. 175; s. Larga, ţin. Hot.; II, p. 454; s. Rusăştii, ţin. Orh.-L.).

Groapă. În timpul RP, de la baza apelativă de substrat groapă au fost înregistrate NF Groapă (II, p. 157, s. Tăbanul; p. 164, s. Cupcenii, ţin. Hot.; II, p. 453; s. Gârlile, ţin. Orh.-L.) şi derivatul onomasticizat Grochină (II, p. 464; s. Saharna, ţin. Orh.-L.).

Grumaz. La est de Prut, de la baza autohtonului grumaz cu transfer în onomastică, a fost înregistrat doar NF Grumeza în antroponimele: Tănase sin Grumeza, Ştefan Grumeza, Onofrei zet Grumeza (II, p. 118; s. Şâşcăuţii, ţin. Hot.).

Leurdă. Prin transferul în onomastică a bazei de substrat leurdă, în s. Feteştii, ţin. Hotinului, a fost înregistrat NF Leordă (de la var. locală leordă) (II, p. 160).

Mare. A fost înregistrat în NF format prin compunere Calmari (cal + mare) (II, p. 451; s. Mimorenii, ţin. Orh.-L.). Se regăseşte şi prin forme derivate în NF Măruş (II, p. 149; s. Cerbicenii, ţin. Hot.) şi Marulă (II, p. 457; s. Dubăsarii, ţin. Orh.-L.).

Măgar. De la autohtonul măgar, în urma transferului în onomastică, avem NF Măgari (II, p. 439; s. Răcea, ţin. Orh.-L.) şi Măgariul (II, p. 162, s. Târnova, ţin. Hot.).

Mărar. Pentru baza apelativă de substrat mărar, în s. Mimorenii, ţin. Orhei-Lăpuşna, a fost înregistrat, în rostire locală, NF Mărau [pentru Măraru] (II, p. 450).

Mânz. În timpul RP, de la baza apelativă a autohtonului mânz, prin transfer în onomastică, au fost înregistrate doar NF formate de la derivate: Mânţog (mânzoc) (II, p. 455; s. Băţănii, ţin. Orh.-L.), Mânzar (II, p. 452; s. Gangura, ţin. Orh.-L.); Mânzatul (II, p. 120, s. Cerlena; p. 169, s. Bălcăuţii, ţin. Hot.).

Moş. Pentru baza apelativă moş, la est de Prut a fost înregistrat doar NF Moşoae în antroponimele Vasâle sin Moşoae (II, p. 159; s. Terebna, ţin. Hot.) 
şi Apostol a Moşoaei (II, p. 472; s. Suslenii, ţin. Orh.-L.), format prin moţiune de la un NF Moş sau Moşu(l), NF înregistrat în Moldova de peste Prut.

Baza apelativă derivată moşneag a fost notată ca determinativ supranume în antroponimele: Dumitru Ţurcan, moşneag (II, p. 465; s. Ciorna, ţin. Orh.-L.); Bârcă, moşneagul (II, p. 113; s. Negrinţii, ţin. Hot.); Andrei a moşneagului (I, p. 400; s. Isacova, ţin. Orh.-L.). Iar ca NF apare articulat în -ul: Moşneagul (II, p. 138, s. Tălmăceiu; p. 141, s. Carlacău; p. 148, s. Sacurenii, s. Clocuşna; p. 161, s. Zăbricenii din ţin. Hot.); în -u: Moşneagu (II, p. 403; s. Hogineştii, ţin. Orh.-L.); în -a: Moşneaga (II, p. 112, s. Mămăliga; p. 120, s. Berestiea; p. 122, s. Cârsteneştii; p. 123, s. Domnenii; p. 125, s. Şălăuţii; p. 130, s. [Ru]javniţa; p. 137, s. Chelmeştii; p. 140, s. Siliştea Mândâcăuţii; p. 149, s. Cerbicenii; p. 170, s. Zalucia din ţin. Hot.; p. 406, s. Cucioaia; p. 418, s. Izbeşte i Cruhlicul; p. 423, s. Săpoteni, s. Bahmutia; p. 429, s. Lozova; p. 434, s. Vălcineţul; p. 469, s. Curlenii din ţin. Orh.-L.).

Murg. $\mathrm{Cu}$ transfer în onomastică, autohtonul murg a fost înregistrat numai ca nume de persoană derivate. Ca posibil prenume apare în antroponimul Murgulet, proprietar (I, p. 117; s. Camina, țin. Cern.). La fel în structura derivatelor, se află în NF Murgociu (II, p. 217, târgul Grecenii; p. 219-220, s. Larga, ţin. Gr.); Murguţă (II p. 117, s. Noua Suliţă, ţin. Hot.), Murguleț (I, p. 119; s. Lahaceni, ţin. Cern.).

Pârâu. În RP autohtonul pârâu a fost notat numai ca NF, mai rar decât era de aşteptat. În antroponimia de la est de Prut apare doar varianta etimologică pârâu, care reprezintă evoluţia normală a cuvântului în limba română (Brâncuş, 1983, p. 107). Astfel, NF Pârâu a fost notat printre antroponimele din ţin. Orhei-Lăpuşna (II, p. 430, s. Străşenii; p. 427, Gheţăoanii; p. 446-447, s. Lăpuşna). Acelaşi fonetism se atestată şi în compusul Pestepârâu (peste prep. + pârâu sb.) din antroponimul Alexa Pestepârâu, înregistrat în s. Ţărujanii, ţin. Hotin (II, p. 127).

Pupăză. Onomasticizat, ornitonimul pupăză a devenit mai întâi supranume. În repertoriul RP este atestat ca antroponim NF doar în două localităţi, fiecare aparţinând la ţinuturi diferite din stânga Prutului. Astfel NF Pupăză a fost înregistrat în ţin. Hotin (II, p. 160, s. Bădrajii) şi în ţin. Grecenii (II, p. 222, s. Macrii). Un caz aparte îl prezintă forma NF Pupinţă din antroponimul Ştefan Pupinţă (II, p. 124; s. Colincăuţii, ţin. Hot.). Acesta ar fi format de la acelaşi radical primar pup-, însă fără reduplicare şi cu alt sufix.

Potrivit datelor RP, numele proprii formate de la baza apelativă pupăză sunt rare în onomasticonul sec. al XVIII-lea. Unul dintre motive ar fi şi simbolismul negativ pe care îl are pupăza în mitologia populară românească (Evseev, 2007, p. 341).

Raţă. Potrivit datelor din RP, autohtonul raţă, la origine un apelativ nume de pasăre, a pătruns în antroponimie ca supranume. În timpul RP, NF Raţă a fost notat cu forma identică apelativului (II, p. 114, s. Costicenii din ţin. Hot.; II, p. 423, s. Săpoteni; p. 442, s. Zgheroaea; p. 448, s. Şişcanii; p. 471, s. Berezlojii din ţin. Orh.-L.). 
Strungă. Majoritatea antroponimelor formate de la apelativul strungă, aflate în repertoriul RP, au tema strug-. Privite din perspectiva formării antroponimelor româneşti, acestea prezintă faze anterioare formării numelui de familie. În cele mai multe dintre antroponime, forma derivată stru(n)gar apare ca supranume indicând asupra ocupaţiei persoanei vizate: Dumitraşcu, strugar, Nicolae, strungar, Vasâle, strungar, (II, p. 116, s. Marşăniţa; p. 165166, s. Rătunda din ţin. Hot.).

Antroponimele ce au forme articulate în -(i)ul sau -u precum Gheorghităa, strugariul (II, p. 114; s. Costicenii, ţin. Hot.) atestă, prin supranumele articulat, un grad mai înalt de individualizare a persoanei purtătoare de antroponim, decât în cazul supranumelor nearticulate.

Exprimând legătura de rudenie directă, acesta poate ţine locul patronimului, cum ar fi în antroponimul Vasâle sin strugariul (II, p. 114; s. Costicenii, ţin. Hot.), în care cea de-a doua componentă strugariul (articulată hotărât) din structura prenume + supranume, atestă o fază de trecere a apelativelor cu funcţie de supranume la numele proprii, NF. De la această fază, prin eliminarea determinativului $\sin$ (,fiul”) din formula dată de filiaţie, s-a ajuns la NF Stru(n)garu(l).

Ţap. Atestat ca nume comun (tapu) în sec. al X-lea, autohtonul ţap, de timpuriu, a cunoscut transferul în onomastică/ antroponimie. Pe parcursul evoluţiei antroponimiei româneşti, acesta (ca şi patronimele Lupul, Ursul ş.a.) era un prenume (probabil, şi poreclă/ supranume), prin care a ajuns ulterior în categoria NF. Ca nume de persoană îl avem notat în antroponimul Ioniţă sân Ţapu (II, p. 443; s. Sălăjenii, ţin. Orh.-L.). În timpul RP, a fost înregistrat şi ca NF, articulat în -ul şi -u: Ţapul (II p. 160; s. Hurghineştii, ţin. Hot.), Ţapu (II, p. 139, s. Cumarău; p. 165-166, s. Rătunda, ţin. Hot.); precum şi în derivatele, la origine supranume/ porecle, evoluate în NF înregistrate în ţin. Orhei-Lăpuşna: Ţapuş [ţap + -uş] (II, p. 454; s. Rusăştii), Ţapeş [ţap + -eş] (II, p. 445; s. Hânceştii).

Theapă. Cuvântul de substrat țeapă (var. ţep, ţăp) se regăsește în NF Ţăpîrlan, avându-şi forma derivată de la ţăp cu suf. -ârl-an (II, p. 218; s. Pelineiu, ţin. Gr.).

Urdă. Apare înregistrat prin derivatul antroponimic Urdilă $[u r d-+-i l-$ ă] din antroponimul Iordachi sin [fiu lui] Urdilă (II, p. 164; s. Chiurchiul, ţin. Hot.), în care Urdilă ocupă locul patronimului. În cazul dat, avem modelul de identificare a copiilor în comunitatea patriliniară la români, exprimat potrivit formulei filiaţiei: prenume + fiu [(al) lui] + numele patern, în care Urdilă ocupă locul patronimului.

Vatră. În actele RP, apelativul de origine autohtonă vatră e atestat ca NF în antroponimul Miron Vatră, avându-şi forma identică cu cea a apelativului (II, p. 157; s. Tiţcanii, ţin. Hot.).

\section{Concluzii:}

1) În Moldova sec. al XVIII-lea, repertoriul antroponimelor şi răspândirea lor teritorială în stânga şi dreapta Prutului, potrivit datelor RP, nu prezintă 
diferenţe mari. Particularităţile de limbă demonstrează unitatea limbii vorbite în acest spaţiu.

2) Relaţiile strânse dintre limbă (în particular, onomastică) şi societatea umană a făcut ca numele de persoană şi numele de locuri să păstreze în arsenalul lor fapte de limbă vechi şi foarte vechi. Faptul dat face ca onomastica, în felul ei, să păstreze şi să utilizeze curent fapte de limbă din diverse epoci istorice.

3) Întrucât onomastica, păstrează şi utilizează fapte foarte vechi, ea poate servi ca metodă de cercetare pentru alte domenii ale limbii, şi nu doar. Operând cu realităţi din viaţa trecută, onomastica păstrează şi fapte de limbă care pot fi puse în relaţie cu substratul limbii române.

4) Fiind strâns legată de problema identificării şi individualizării fiecărui membru al comunităţii, constituirea antroponimelor, reflectă şi forme perpetuate din substrat.

\section{Referințe bibliografice:}

1. BRÂNCUŞ, Grigore. Cercetări asupra fondului traco-dac al limbii române. București, 1995.

2. BRÂNCUŞ, Grigore. Vocabularul autohton al limbii române. București, 1983.

3. EVSEEV, Ivan. Dicţionar de simboluri. Bucureşti, 2007.

4. КОТЕNКО - КОТЕНКО, И. А., МОХОВ, Н. А., СОВЕТОВ, П.В.О тенденции роста народонаселения Молдавии в эпоху феодализма. În: Ученые записки, том VI (серия историческая). Chişinău, 1957.

\section{Surse:}

Moldova în epoca feudalismului. Recensămintele populaţiei Moldovei din anii 1772-1773 şi 1774. Volumul al VII-lea, părţile I şi II. Chişinău, 1975.

\footnotetext{
Abrevieri:

RP - recensământul populaţiei,

$\mathrm{NF}$ - nume de familie,

ţin. Cern. - ţinutul Cernăuţii,

ţin. Hot. - ţinutul Hotinului,

ţin. Gr. - ţinutul Grecenii,

ţin. Orh.-L. - ţinutul Orhei-Lăpuşna,

ţin. Sor. - ţin. Sorocii.

Notă: Articolul a fost realizat în cadrul proiectului de cercetare 20.80009.1606.01 Valorificarea științifică a patrimoniului lingvistic național în contextul integrării europene, Institutul de Filologie Română „B. P.-Hasdeu” al MEC.
} 